\title{
Asymptomatic Anomalous Collateral Artery Derived from the Left Internal Thoracic Artery: Established Strong Collateral Circulation
}

\author{
Patrick J. Buchanan, ${ }^{1,2}$, Olga Malakhova1 \\ ${ }^{1}$ Department of Anatomy and Cell Biology, University of Florida, Gainesville, USA \\ ${ }^{2}$ Department of Surgery, Division of Plastic and Reconstructive Surgery, University of Florida, Gainesville, USA \\ Email: buchanap@med.umich.edu
}

Received 25 April 2014; revised 28 May 2014; accepted 3 June 2014

Copyright $@ 2014$ by authors and OALib.

This work is licensed under the Creative Commons Attribution International License (CC BY).

http://creativecommons.org/licenses/by/4.0/

(c) (i) Open Access

\begin{abstract}
An anomalous collateral artery was found during the dissection for the pectoralis major myocutaneous flap procedure. This anomalous collateral artery was stemming from the left internal thoracic artery. It is believed that this collateral was formed secondary to congenital aortic coarctation causing abnormal growth of the left fourth aortic arch. This is the first reported case of such a collateral artery in recent literature.
\end{abstract}

\section{Keywords}

Pectoralis Major Myocutaneous Flap, Anomalous Collateral Artery, Aortic Coarctation Collateral Artery, Left Internal Thoracic Artery, Left Fourth Aortic Arch

Subject Areas: Anatomy \& Physiology, Developmental Biology, Surgery \& Surgical Specialties

\section{Introduction}

Coarctation of the aorta is a rare congenital malformation that affects the wall of the aorta and as a result of constriction of the aorta [1]. It is estimated to occur in $0.3 \%$ of all live births [2]. That is, coarctation of the aorta affects 1:2.500 live births in the USA [3] [4]. It tends to affect males more than females [5]. The pathogenesis of aortic coarctation remains unclear. However, the most widely accepted explanation of this phenomenon is an abnormal growth of the left fourth aortic arch. Coarctation of the aorta may occur adjacent to ductus arteriosus 
or on the proximally (preductal) or distal (postductal) positions.

\section{Case Discussion}

The anomalous collateral (AC) artery was found during the dissection of a pectoralis major myocutaneous flap procedure. The embalmed cadaver was an 80-year-old female who died from corticobasal degeneration and diabetes. The cadaver had no known visible history of surgery or chest trauma. During dissection of the left pectoral region the strongly tortuous AC artery was discovered. This artery was passing superficially to the pectoralis major muscle with the most inferior aspect level with the fifth rib. The AC artery then traversed the axilla and joined the left brachial artery (Figure 1). This AC artery was stemming from the left internal thoracic artery in the third intercostal space. It then crossed the medial antebrachial cutaneous nerve and connected to the brachial artery. The diameter of the left brachial artery was measured above and below the connection of the AC artery. These diameters measured $2.2 \mathrm{~mm}$ and $3.5 \mathrm{~mm}$, respectively. Using an intra-arterial gauge, the AC artery measured $37.4 \mathrm{~cm}$ in length and $3 \mathrm{~mm}$ in diameter. The right pectoral region was also dissected to provide comparison. The right pectoral anatomy did not show any abnormal appearances.

The aortic arch and thoracic aorta were dissected. The aortic arch was shown to have slight changes in the diameter $(2.8 \mathrm{~cm}$ and $3.7 \mathrm{~cm}$, respectively) just below the level of the ligamentum arteriosum. An anatomically normal left subclavian artery was dissected at the level of the superior mediastinum. However, in the interscalenus space the left subclavian artery becomes $2.2 \mathrm{~mm}$ in diameter. The left subclavian artery continued on as the

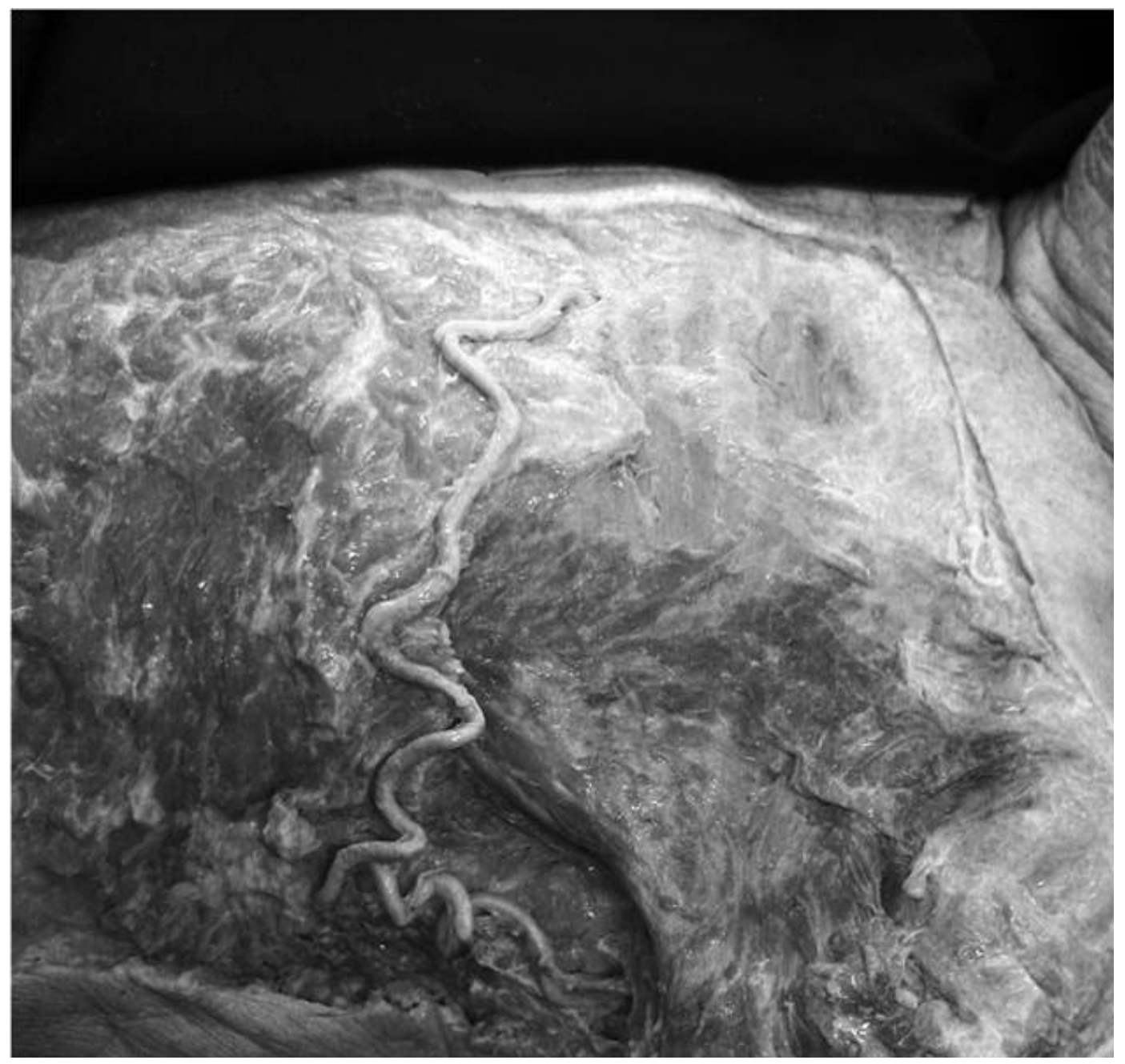

Figure 1. The anomalous collateral artery crossing the left pectoralis major muscle. The cadaveric head is towards the right of the image. The picture is taken viewed from the left axilla. 
left brachial artery with the same diameter. It was not until the AC artery joined the brachial artery that the diameter of the vessel enlarged to $3.5 \mathrm{~mm}$. This is the first reported case in recent literature to the best of our knowledge. We have shown an AC artery between the left internal thoracic and left brachial artery, presumably as a result of an abnormal growth of the left fourth aortic arch.

\section{References}

[1] Kardos, A., Musialek, P. and Csanády, M. (1998) Coronary Artery-Descending Aorta Fistula as Unusual Collateral in a Patient with Postductal Coarctation. Catheterization and Cardiovascular Diagnosis, 44, 431-433. http://dx.doi.org/10.1002/(SICI)1097-0304(199808)44:4<431::AID-CCD16>3.0.CO;2-L

[2] Schoenwolf, G., Brauer, S. and Francis-West, P. (2009) Larsen’s Human Embryology. 4th Edition, Churchill Livingston, London, 415-418.

[3] Anderson, R., Baker, E.J., Macartney, F.J., Rigby, M.L., Shinebourne, E.A. and Tynan, M. (2002) Pediatric Cardiology. 2nd Edition, Churchill Livingstone, London, 1353-1382.

[4] Kenny, D. and Hijazi, Z.M. (2011) Coarctation of the Aorta: From Fetal Life to Adulthood. Cardiology Journal, 18, 487-495. http://dx.doi.org/10.5603/CJ.2011.0003

[5] Fyler, D.C., Hellenbrand, W.C. and Cohn, H.E. (1980) Report on the New England Regional Infant Cardiac Program. Pediatrics, 65, 375-461. 